\title{
Correction to: Subdural hemorrhage rebleeding in abused children: frequency, associations and clinical presentation
}

\author{
Jason N. Wright ${ }^{1,2} \cdot$ Timothy J. Feyma ${ }^{3}$. Gisele E. Ishak ${ }^{1,2}$ - Sergey Abeshaus ${ }^{4}$ - James B. Metz ${ }^{5}$ Emily C. B. Brown ${ }^{2,6}$. \\ Seth D. Friedman ${ }^{1,2} \cdot$ Samuel R. Browd ${ }^{2,7} \cdot$ Kenneth W. Feldman ${ }^{2,6}$ (1)
}

Published online: 22 May 2020

(C) Springer-Verlag GmbH Germany, part of Springer Nature 2020

\section{Correction to: Pediatric Radiology (2019) 49:1762-1772 https://doi.org/10.1007/s00247-019-04483-5}

The original article included a statement which is not fully accurate. This correction clarifies the original statement.

In the introduction of our paper on subdural rebleeding [1], we stated that "radio-tagged red blood cells injected into the lumbar subarachnoid space appear rapidly within chronic SDHs [subdural hemorrhages], suggesting transfer from the subarachnoid space" and cited Ito et al. [2] and Zouros et al. [3]. Ito et al. [2], instead, injected radio-tagged red blood cells into the patients' vasculature. They recovered those cells from within chronic subdural hemorrhages at surgery 6-24 h later. This suggested ongoing bleeding from the subdural membranes' vasculature into the subdural cavity. Zouros et al. [3], instead, injected radiotracer into lumbar spinal fluid and subsequently recovered it from externalized subdural cavity

The online version of the original article can be found at https://oi.org/ 10.1007/s00247-019-04483-5

Kenneth W. Feldman

kfeldman@uw.edu

1 Department of Radiology, Seattle Children's Hospital, Harborview Medical Center, Seattle, WA, USA

2 University of Washington, Seattle, WA, USA

3 Department of Neurology, Gillette Children's Specialty Health Care, St. Paul, MN, USA

4 Department of Neurosurgery, Rambam Health Care Campus, Haifa, Israel

5 Department of Pediatrics, University of Vermont School of Medicine, Burlington, VT, USA

6 Department of Pediatrics, Children's Protection Program, M/S SB-250, Seattle Children's Hospital, Harborview Medical Center, 4800 Sand Point Way NE, Seattle, WA 98105, USA

7 Department of Neurological Surgery, Seattle Children's Hospital, Harborview Medical Center, Seattle, WA, USA drains. Assuming lack of transfer through intact arachnoid, this implied the existence of subarachnoid tears in communication with the chronic subdural cavity.

Although our statement was incorrect, it remains correct that the Ito et al. [2] study, in particular, supports ongoing bleeding from the subdural neo-membranes' vasculature into the subdural cavity. The Zouros et al. [3] data provide a possible explanation for some early mixed density subdurals.

\section{References}

1. Wright JN, Feyma TJ, Ishak GE et al (2019) Subdural hemorrhage rebleeding in abused children: frequency, associations and clinical presentation. Pediatr Radiol 49:1762-1772

2. Ito H, Yamamoto S, Saito K et al (1987) Quantitative estimation of hemorrhage in chronic subdural hematoma using ${ }^{51} \mathrm{Cr}$ erythrocyte labeling method. J Neurosurg 100:862-864

3. Zouros A, Bhargava R, Hoskinson M, Aronyk KE (2004) Further characterization of traumatic subdural collections of infancy. $\mathrm{J}$ Neurosurg Pediatr 100:512-518

Publisher's note Springer Nature remains neutral with regard to jurisdictional claims in published maps and institutional affiliations. 